\title{
Help-seeking Behaviours among Haemophilia Community in Central Iran: A Qualitative Study
}

Mehrdad Zeinalian ${ }^{1 *}$, Effat Merghati-Khoei², Sayyed Ali Azin ${ }^{3}$, Ashraf Samavat ${ }^{4}$ and Morteza Hashemzadeh-Chaleshtori ${ }^{1}$

${ }^{1}$ Genetic Office, Health Deputy, Isfahan University of Medical Sciences, Iran

${ }^{2}$ Department of Public Health \& Community Medicine, Tehran University of Medical Sciences, Iran

${ }^{3}$ Health Sciences Research Centre, Tehran

${ }^{4}$ Genetic Office, Health deputy, Iranian Ministry of Health, Tehran

\begin{abstract}
Objectives: Impressive factors affecting help-seeking behaviours and its construction have a determinant role to design health interventions; therefore we run a qualitative study to explore them for the first time before implementing Iranian Program for Control and Prevention of Haemophilia (IPCPH) in Iran.

Methods: We applied an ethnographic approach in this study. Participants were 61 haemophilia patients and their first degree relatives in Isfahan Province (center of Iran). We organized them in 7 Focus Groups Discussions (FGD). Data analysis was performed using thematic and discourse analysis.

Results: We explored some impressive factors affecting help-seeking behaviours of the participants including: self-efficacy, isolation and privacy concluded from stigmatization, religious beliefs, gender-based discrimination, and familial contexts such as family advocacy, poverty, cultural characteristics, and previous experiences on haemophilia disease.

Conclusion: We should develop IPCPH by promoting help-seeking behaviours of haemophilia community through some interventions such as: comprehensive counselling, economic advocacy, and promoting healthrelated attitudes. Meanwhile, we can help the haemophilia community to get rid of social restrictions through public education toward haemophilia and its preventive methods.
\end{abstract}

Keywords: Qualitative study; Haemophilia; Help-seeking behaviour; Iran

\section{Introduction}

A large part of health system budget is allocated consistently in all countries for haemophilia [1]. Thus, preventive interventions are suggested to reduce disability, drug consumption in patients, and incidence of disease throughout the world $[2,3]$.

Some interventions such as genetic counselling and testing, prenatal diagnosis, and on-demand therapeutic abortion are basic parts of a preventive program for genetic conditions like haemophilia. Meanwhile, attitudes and beliefs of patients and their families toward health-related well-being affect preventive interventions. These beliefs, even in developed countries, are serious challenges against prevention of genetic conditions [4-6]. Some studies have revealed disagreement of most mothers against therapeutic abortion [6].

The Knowledge of people about prevention methods, specifically genetic testing, affects their attitudes toward genetic counselling and therapeutic abortion [7]. The privacy policy and confidentiality are important issues affecting attitudes and beliefs of haemophilia families, especially in parents, about their help-seeking behaviours [8] .

We designed a qualitative study to explore construction of helpseeking behaviours in haemophilia patients and their families, hoping the results may be helpful to solve some problems of Iranian program for control and prevention of haemophilia (IPCPH). In this article we argue some of the results of this research.

\section{Materials and Methods}

Our approach in this qualitative study was ethnography. Sampling process was purposive. A key informant of Isfahan Haemophilia Society helped us to select and invite our samples. The participants were 61 haemophilia families living in Isfahan Province. They included the patients' wives, mothers, daughters, sisters, and fathers which were organized in seven groups (patients in two groups), as Focus Group Discussion (FGD). Each FGD consisted of 6-12 participants.

Data collection was performed from January to December 2012 through 7 sessions, averagely 1.5 to 2 hours per session. FGDs were conducted with semi-structured Index (Table 1).

We analyzed the data by thematic and discourse analysis methods. Coding process was applied independently for every FGD's text, and original themes were determined through interpretive-thematic method.

\section{Results}

We classified the results under five main domains: haemophilia and social performance, haemophilia and gender, haemophilia and selfefficacy, haemophilia and prevention, haemophilia and familial context. According to thematic analysis, some concepts have determinant role in processing of participants' perception about haemophilia and their help-seeking behaviours.

*Corresponding author: Mehrdad Zeinalian, Department of Molecular Medicine, Cellular and Molecular Research Center, Shahrekord University of Medical Sciences, Iran, Tel: +9809131098411; Fax: 9803114485658 E-mail: zeinalian_mehrdad@yahoo.com

Received March 06, 2014; Accepted March 31, 2014; Published April 05, 2014

Citation: Zeinalian M, Merghati-Khoei E, Azin SA, Hashemzadeh-Chaleshtori M (2014) Help-seeking Behaviours among Haemophilia Community in Central Iran: A Qualitative Study. J Blood Disorders Transf 5: 214. doi: 10.4172/2155-9864.1000214

Copyright: (c) 2014 Zeinalian M, et al. This is an open-access article distributed under the terms of the Creative Commons Attribution License, which permits unrestricted use, distribution, and reproduction in any medium, provided the original author and source are credited. 


\begin{tabular}{|c|c|c|c|}
\hline FGD's No & Participants' class & Participants' Number & Time (on minute) \\
\hline 1 & Patients' sisters & 12 & 82 \\
\hline 2 & Patients' daughters & 7 & 94 \\
\hline 3 & Patients' wives & 6 & 104 \\
\hline 4 & Patients' mothers & 11 & 106 \\
\hline 5 & Patients (Group 1) & 7 & 105 \\
\hline 6 & Patients (Group 2) & 7 & 127 \\
\hline 7 & Patients' fathers & 11 & 83 \\
\hline
\end{tabular}

Table 1: Characters of Focus Group Discussions.

They include: religious beliefs, familial socio-economic state, physical and psychological complications, social stigma, secrecy and isolation, and familial advocacy.

The results also show that religious beliefs of the participants would affect their behaviour and performance toward the disease or their carrier status. Also the results reveal that self-efficacy of individuals motivates them to improve their performance on help-seeking behaviours.

Moreover, social stigma is one of the main reasons for isolation and secrecy among the patients and their families. So it can affect significantly their performance. Meanwhile, social stigma depends on populations' knowledge toward the disease and its features.

The age of marriage is the best time for genetic testing and counselling of suspicious carriers, according to the most participants. Otherwise, the privacy and confidentiality must be observed, especially by the parents.

\section{Discussion}

\section{Haemophilia and social performance}

Haemophilia can exert a significant effect on social performance of patients and their families, because it leads to some social and cultural impressive factors on perceptions and behaviours of patients and their families [9].

Social stigma: One of the strongest stressors in haemophilia patients and carriers is a concern about people's judgment toward their special conditions. Concealing the disease of others likely is derived from this concern. One of the most important worrying issues among them is fear of future due to loss of some social situations because of their disability or carrier status. These may create some psychosocial and functional disorders in the patients and their families $[10,11]$.

"Mahin" 22-year-old, a patient's daughter:

«.... I've really a big concern that what a future I'll have? And with whom I should survive my life? Will my suitor accept when he knows may be father a sick kid?!....» (FGD2)

Haemophilia has been manifested as an obstacle to the life of $\mathrm{Mr}$ "Omid", a severe 29-year haemophilia patient, which has impressed strongly his self-confidence and decision making.

“... I've neither gone to matchmaking yet, nor thought about it.... I think marriage is an ocean in which I can't swim. .... Essentially it could neither be spoke nor imagined. What we say in matchmaking?! The man would be ashamed even in talking about it.... » (FGD6)

Felt stigma or feeling of guilt is one of the most important concepts in psychology. Some authors have emphasized on its importance to develop psychosocial performance in people, particularly patients $[8,12,13]$.
Secrecy and social isolation: The secrecy and social isolation were emphasized by most patients and their families as important effective concepts on their health-related behaviours. These themes have been concluded of some qualitative studies on chronic conditions as negative effective factors on help-seeking behaviours among the patients and their families $[5,6]$. Given the fact that haemophilia patients don't present any visual sign in their appearance, apparently most patients and their families aren't willing to disclose their disease due to fear of people's reactions.

\section{Mr "Sohrab" a severe 21-year-old haemophilia patient:}

«.... Sometimes I couldn't attend my class because of my medical problems and I've so retarded from my course. I haven't told about my condition to the friends...they ask me consistently about my limp's cause and I tell them I can't walk properly because of an accident in the past. » (FGD5)

Fearing of isolation and rejection by the others is another expressed reason by some participating patients in the study as a proof for concealing their disease.

"Joseph" a severe 18-year-old haemophilia patient:

«... I've hidden my disease from my friends, otherwise I'm not comfortable. For example, if they are informed about my problem, may be they exclude me when they want to play or go to a picnic or mountain, etc. .. When my leg hurts in the soccer and catches painful bleeding, I'd try nobody be informed about it... to not to aware anyone of our state, we have to tell lies regularly. » (FGD5)

Meanwhile, there were some instances in opposition to secrecy among patients participating in research in which they believed people awareness of their disease is one protective factor to support them, although the most participants were agreed with confidentiality.

"Benyamin", a severe 23-year-old haemophilia patient:

“... Concealing the disease has no benefit. Because if I keep somebody posted, he or she would be eventually aware of my disease, so I describe it for him and he'd also watch me friendly. » (FGD5)

"Tayyebeh", a 33-year-old housewife, emphasized unhiding her son's disease from school and university authorities to care better about the patient.

«.... When my son was going to school, we told school authorities his problem and they were aware of it. Even sometimes, his teachers were picking him up from school to home by their cars. Now also, we have stated his problem for his dorm manager and he is satisfied himself of it .....» (FGD4)

This mother, however, emphasized on this point that despite their family and friends' awareness of her son's state, there is no saying about his disease and its problems among the family due to their attention to how dealing with their sick child.

Financial poverty: Various studies have shown that some economic factors significantly affect health-related behaviours in the patients and their families. The most important of these factors include financial poverty, low income, and lack of appropriate insurance protection Flood [14]. In addition, a deep effectiveness was explored for employment of patients in disease-adjusted positions to promote their quality of life and life satisfaction [15].

“Sakineh", a housewife, patient' wife: 
«...... Now he (my husband) has been unemployed because of the severity of his physical problems since four years ago, and our alimony is provided from his capital. But it will be spent at soon....» (FGD3)

Apparently, sufficient income and favourable economic level are effective to promote help-seeking behaviours.

The religious beliefs: Our results indicated that the participants' beliefs toward religious concepts would impact their personal and social performance through self-efficacy promotion. It would be achieved via "faith in dynamic adjustment" and "submission and trust". These can improve familial communications, especially in issues such as marital relations.

\section{"Pedram", a 24-year-old haemophilia patient:}

«...... If you have trust in God, you have no need to worry. It isn't slogan, and if your heart is clear and with God, God will help itself you, I've found this, and I hope you reach it too. ....» (FGD6)

Ms. "Nastaran", a18-year-old sister of a severe haemophilia patient:

“.. Although I may be carrier of haemophilia, my trust to God has removed my worries. I believe we will be able to create our future well by trust in God and using preventive methods. " (FGD2)

Need to religion means need to an orientation and reference model for belief and faith. Nobody may be found without this need [12]. Religious beliefs are considered as well as basic determinants to promote quality of life and health related well-being [16,17].

\section{Haemophilia and prevention}

Some interventions such as genetic counselling and testing, and on-demand therapeutic abortion are all the original integrated parts of prevention programs on genetic diseases like haemophilia. So exploring attitudes and beliefs of patients, carriers, and their families toward them is very determinative to design interventional programs for haemophilia and other similar genetic diseases [5,18-20].

IPCPH and genetic testing: Evaluating attitudes of haemophilia families toward genetic counselling and testing, some studies have shown positive perceptions in these families to participate in healthrelated interventions Markova et al. [21]. According to a qualitative study in Australia, in spite of considerable knowledge of participants about genetic testing, there was confusion about who needed to be tested. Most thought genetic testing was essential for adolescent girls to find out carrier status to preparing families for a haemophilic child, rather than terminating a pregnancy or not to have children [19].

Most participants in our study had a positive attitude toward IPCPH. Our findings indicated their demanding to implement IPCPH, as soon as possible.

"Sohrab" collegian, 20-year-old, a severe haemophilic patient:

«.... Prevention program of haemophilia is very good. We have made a compromise with this disease from our birth, and know all the problems around it, so we will yearn for this project...» (FGD5)

Although there is a positive attitude in most families toward $\mathrm{PCPH}$, it seems the majority of them still have insufficient information about the preventive methods. It will likely have negative effects on their help-seeking behaviours.

"Maria”, 22-year-old, a patient's daughter:

«....I have so worries about the future in the past, but once a few years ago I came with my dad to the hospital and saw a pregnant woman with haemophilia fetus referred for abortion, then my worries a little were removed......» (FGD2)

There were some families in our study in which carrier mothers had not been supported by their husbands for preventive interventions. Apparently, blaming the mothers by their husbands has a more considerable role than financial problems to keep them away from involving in prevention process with their carrier wives.

"Soudabeh" 50-year-old, housewife, mother of a patient:

«...... My husband continuously groans and makes excuse. Every time my son bleeds, his father blows his top and gives me hell: Why did you marry despite your problem?!.....» (FGD4)

This theory is invigorated by comments of some patients' fathers in FGD7 about necessity of genetic testing performance even in exorbitant cost.

“Rostam" 48-year-old, retired, a patient's father:

«..... I haven't done genetic testing for my married daughter, because I have no information about it, but now that I knew, even if my daughter was still unmarried, surely I'd do it. Its cost is not important, it's better than that one new haemophilia patient would be born. .....» (FGD7)

According to heavy cost of genetic testing and financial problems in the most families, it seems attitude of breadwinner in family, usually fathers, must be invigorated deeply to conduce proper performance of help-seeking behaviour.

Attitude and practice toward therapeutic abortion: Given the abortion is a stressful event for all pregnant mothers, there are different attitudes toward therapeutic abortion among various societies. For example, in one study on a Pakistani population, $15 \%$ were unwilling to consider termination of pregnancy in any circumstances. Most respondents $(63 \%)$ were in favor of abortion if fetal death was impendent as a result of a congenital disorder [2].

In a Malaysian study, Out of 116 respondents, 83 persons were agreeable for prenatal diagnosis, but only 33 persons agreed to both prenatal diagnoses followed by termination of affected fetuses Ngim et al. [22].

In our study, most participants thought the therapeutic abortion as a so troublous procedure for mothers, although they emphasized on its essential role to prevent from incidence of new cases.

"Setareh" 22-year-old, collegian, a patient's daughter:

«..... It is very difficult for a mother whose fetus who has been consisted of her blood and flesh, would be aborted; but if I was instead this mother and had watched problems of my sick father and toils of my mother due to sickness of my father, I'd never consent a new haemophilia patient to be added to our previous patients and this cycle continues. Therefore, I will agree with it, despite its severities....» (FGD3)

Given the religious texture of Iranian populations and their imitation of religious authorities, the role of "Fatva", a religious sentence of a Marja (religious leader), to convince people of therapeutic abortion must be significantly considered. Now, according to all Marjas' Fatvas in Iran, therapeutic abortion is approved in particular conditions such as an affected fetus with haemophilia. 
"Fatimah", householder, a 28-year-old patient's mother:

«..... I thought abortion was religiously unlawful, but right now I knew that it's legal in haemophilia. Then I'll do it for my next pregnancy, if necessary. ...» (FGD4)

What is the best time for genetic testing of carriers?: Referring time of suspicious carriers to genetic testing is one of the most important challenges in IPCPH, because of potential stigma and some social misconduct against carrier females. Of course there is discrepancy among various societies. Where genetic testing is possible before the child reaches the age of consent, most families effort to determine time of carrier status testing. The main question is that weather they must have their daughters tested during childhood, specifically before puberty, or wait until they are adults and can make the decision themselves. Anyway, carrier status testing should be performed before pregnancy Carvalhosa et al. [23].

In two sessions with patients' daughters and sisters (FGD1, 2) all participants emphasized on genetic testing in early puberty age, certainly before the marriage age. They expressed having enough time for coping with their conditions as the main reason for this idea.

“Mina”, a 24-year-old patient's sister:

“... I think age 15 is the best time for carrier status testing, because the person is matured in this time and has enough perception to accept the fact. Moreover, there is some distance from this age till marriage time to prepare by increasing her knowledge...» (FGD2)

Genetic testing is delayed by some families as a form of denial, or to look after the child and themselves from excessive concerns [23]. A few participants in our study believed that the best time for testing is immediately before the marriage. They mentioned avoidance of unnecessary concern in the families as the most important reason for their thought.

"Kokab”, a 23-year-old patient's sister: “... I think if they know sooner, their worries will be increased, but before marriage is better. Early understanding not only won't solve the problem but also provokes concerns...» (FGD1)

Interestingly mothers had a different opinion than their daughters. Although almost all of them emphasized on necessity of genetic testing to determine carrier status of at-risk girls before their marriage, they believed that the childhood period was the best time to do these tests. They also believed that early genetic testing neither did increase parents' worries, nor decrease their concerns, and conduct them to design a good future for their daughters. Participant mothers also emphasized on confidentiality of carrier status of their daughters until the girls reach puberty.

“Tayyebeh" a housewife, 43-year-old, a patient's mother:

“... I think genetic testing should be done in childhood for children, so the parents would be aware of their status. Then if she is carrier, the parents can inform gradually their daughter until she reaches puberty and makes a compromise with the fact ....» (FGD4)

It seems worries due to awareness of the fact are associated to an unsolvable condition that there is no solution to get rid of its undesirable results. For example, in patients with incurable diseases such as advanced cancer, awareness of disease will intensify worries among them. In carrier members of haemophilia families, however, the knowledge induces some appropriate preventive behaviour Pandey et al. [19], Nazzaro et al. [18].
"Maria", a 22-year-old patient's daughter:

«....I was too worried about the future in the past, but once a few years ago I came with my dad to a hospital and saw a pregnant woman with affected fetus referred for abortion, then my worries a little were removed......» (FGD2)

\section{Haemophilia and gender-based discriminations}

The sexuality is consisted of behaviours, social roles and ideas that are defined by every culture for men and women. There are some formed thoughts related to gender roles for both sexes in society which determine the range of expectations of them Nercissians (2004) [24]. Females in haemophilia families are exposed to higher social stigma and psychosocial, emotional tension due to the specific pattern of transmission in haemophilia (X-linked recessive).

"Yasamin", a 48-year-old patient's mother:

«.... I'm mother of two haemophilia patients. My husband always tells me: off, while my kids have been only under my care, of birth until now. He hasn't even taken my children to a doctor office so far! Their entire burden has been on my shoulder. But despite this, my husband always blames me.....» (FGD4)

\section{Haemophilia and familial context}

We found some factors such as familial advocacy, experience of haemophilia in close kindreds, and familial knowledge toward the disease and its problems could significantly affect help-seeking behaviours of the haemophilia families and their health-related wellbeing. This is the same that various studies have also emphasized it Thomas et al. [6], Gregory et al. [25] and Beeton et al. [26].

Family advocacy: The study shows that family support, specifically parents, of patients and carriers has a determinant role to form their attitude and behaviours toward disease and prevention. The parents naturally have a determinant role to support their sick or carrier children in psychological, emotional, and physical aspects. Meanwhile, the disorder of children has a significant, negative effect on quality of life and psychological condition of their parents [24].

"Tayyebeh" 43-year-old, mother of a severe haemophilic patient:

".... I think the role of parents is very important to improve children's spirit. We have never treated with our sick son as a patient and always tried to give him spirit. .... Now my son goes easily to picnic, even mountain, with his peers, and he hasn't any problem... »(FGD4)

Haemophilia in family history: Haemophilia-related experiences in the family, and of course quantity and quality of these experiences, are important to construct behaviours of patients and their families. We studied the role of these experiences in behaviour of patients and their families from different aspects.

Families without history of disease in which a patient is born for the first time (new case), more stress and psychological problems are created by haemophilia. Apparently, coping with conditions is occurred in families with history of disease-related experiences that is effective to reduce stress and psychological problems, specifically among female members of haemophilia families who are carriers or bear an affected child.

"Soudabeh", a 46-year-old patient's mother:

“... We're five sisters and only I'm carrier. I was informed of this fact at my child's birth, and it created many psychological problems 
for me, and my husband and his family put the blame on me (crying mood) ....» (FGD4

It seems a history of haemophilia in kindreds of carrier mothers leads to impose blames on them by their husbands due to their previous awareness of the risk of bearing a sick child.

But in a family without history of the disease, the husband finds his wife innocent because there is no awareness of carrier status in her family.

Of course, other factors such as religious beliefs also have a determinant effect about which we already discussed.

“Tahereh", a 45-year-old patient's mother:

“... I'm single mother in our family that my child has haemophilia... I have no problem with my husband. Although all of his family blame me, he says "It has been God's ordinance." But I've had many problems with my husband's family, especially his mother and sister... They attempted so much to convince him for second marriage, but my husband didn't accept not at all.... (FGD4)

Interestingly, after two experiences of healthy birth, the pressure of her husband's family has been removed:

"... When the God gave us two fit girls after our sick son, the pressure from my husband's family was removed ....»

Haemophilia and family knowledge: Knowledge and awareness of the disease and its prevention methods is one of the most important concepts in family context which is highly effective in their attitude and practice toward haemophilia [17]. We explored some impressive factors to promote help-seeking behaviours of haemophilia families to prevent disease and improve their quality of life. The knowledge about disease and its different medical aspects was one of the most important of these factors, specifically toward the patients care and new preventive methods.

“Tahmineh" 38-year-old, wife of a severe hemophilic patient:

“... Now that I knew there are some tests to ensure my child health, my mind became calm and my concerns were decreased. "

Some studies on chronic conditions have shown that if knowledge of the family, especially parents, increases, their quality of life will promote Nazzaro et al. [18], Kang et al. [27]. Increasing the knowledge will improve patients' care in family to a scientific and accurate manner. So, it is a main factor to prevent of disability in patients and improve their quality of life. If the parents are informed about proper methods of care, their sick children will mature under scientific care, and enjoy from an acceptable quality of life compared with their healthy peers.

"Batoul" 42-year-old, mother of a severe haemophilic patient:

".... I and my husband learned in counselling sessions not to treat with our sick child as a patient. We always try to give him selfconfidence. ... We are so careful about his physical and psychological conditions. Our son, now, is a healthy student at engineering University with an excellent degree.... » (FGD4)

\section{Conclusion}

We could explore in this study, an explanatory model for helpseeking behaviours of haemophilia patients and their families within Central Iran. This model explains structure of perceptions and behaviours of the Iranian haemophilia community for the first time (Figure 1).

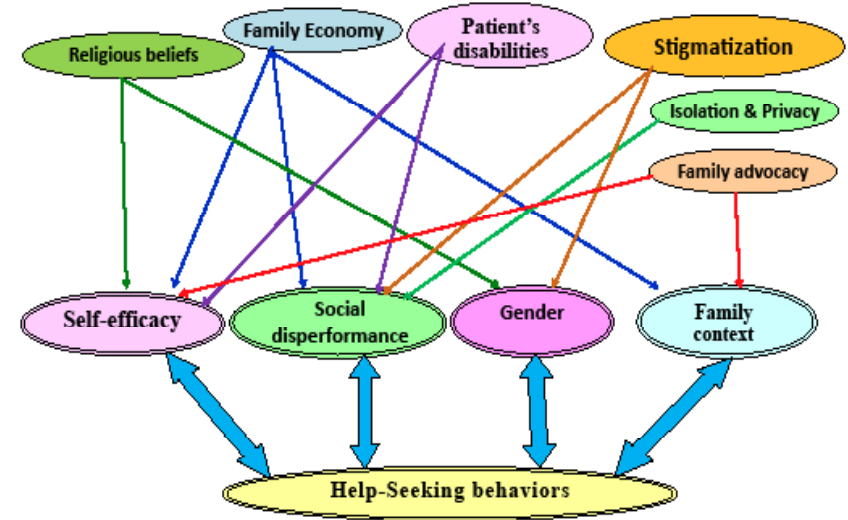

Figure 1: Explanatory model for help-seeking behaviors of hemophilia community in Isfahan (Central Iran).

We conclude accordingly that health-related interventions within haemophilia in our population cannot be realistic and effective in practice, regardless to determinant factors of their helpseeking behaviours. The quality of life and help-seeking behaviours of haemophilia community would be promoted by comprehensive counselling of the patients and their families, including all aspects of personal and social life. Moreover, developing insurance services and providing necessary facilities for professional education and employment have a considerable, impressive effect to improve healthrelated well-being and help-seeking behaviours among haemophilic community.

\section{Ethical standards}

We obtained ethical approval for the study from the Research Ethics Board of the Research Deputy of Isfahan University of Medical Sciences. The confidentiality was observed toward the participants, and their consent was obtained to publish their quotations' analyses.

\section{Acknowledgment}

We appreciate the helpful cooperation of Genetic Office in Iranian Ministry of Health, Health Deputy of Isfahan University of Medical Sciences, the hemophilia ward of Sayyedo-shohada Hospital in Isfahan, hemophilia society, and all hemophilic patients and their families in Isfahan.

\section{References}

1. Harper P, Brasser M, Moore L, Teague L, Pitcher L, et al. (2003) The challenge arising from the cost of haemophilia care: an audit of haemophilia treatment at Auckland Hospital. N Z Med J 116: U561.

2. Antunes SV (2002) Haemophilia in the developing world: the Brazilian experience. Haemophilia 8: 199-204.

3. Srivastava A, Chuansumrit A, Chandy M, Duraiswamy G, Karagus C (1998) Management of haemophilia in the developing world. Haemophilia 4: 474-480.

4. Ranta S, Lehesjoki AE, Peippo M, Kääriäinen H (1994) Hemophilia A experiences and attitudes of mothers, sisters, and daughters. Pediatr Hematol Oncol 11: 387-397.

5. Markova I, Wilkie PA, Naji SA, Forbes CD (1990) Self- and other-awareness of the risk of HIVIAIDS in people with haemophilia and implications for behavioural change. Soc Sci Med 31: 73-79.

6. Thomas S, Herbert D, Street A, Barnes C, Boal J, et al. (2007) Attitudes towards and beliefs about genetic testing in the haemophilia community: a qualitative study. Haemophilia 13: 633-641.

7. Karimi M, Peyvandi F, Siboni S, Ardeshiri R, Gringeri A, et al. (2004) Comparison of attitudes towards prenatal diagnosis and termination of pregnancy for haemophilia in Iran and Italy. Haemophilia 10: 367-369. 
Citation: Zeinalian M, Merghati-Khoei E, Azin SA, Hashemzadeh-Chaleshtori M (2014) Help-seeking Behaviours among Haemophilia Community in Central Iran: A Qualitative Study. J Blood Disorders Transf 5: 214. doi: 10.4172/2155-9864.1000214

8. Barlow JH, Stapley J, Ellard DR (2007) Living with haemophilia and von Willebrand's: a descriptive qualitative study. Patient Educ Couns 68: 235-242.

9. Santagostino E, Messina M, Tagliaferri A, lorio A, Morfini M (2013) Haemophilia at various stages of life: design of new therapeutic strategies through an interactive course--the Kogeniale project. Blood Transfus 11: 272-280.

10. Cassis FR, Querol F, Forsyth A, lorio A; HERO International Advisory Board (2012) Psychosocial aspects of haemophilia: a systematic review of methodologies and findings. Haemophilia 18: e101-114.

11. Cassis FR (2007) Psychological care for people with haemophilia. Treatment of haemophilia 44

12. Cynthia A, Donald W, Holtzman NA, Winkelstein JA (2006) How does the mode of inheritance of a genetic condition influence families? A study of guilt, blame, stigma, and understanding of inheritance and reproductive risks in families with X-linked and autosomal recessive diseases. Genet Med 8: 234-242.

13. Gausset Q, Mogensen HO, Yameogo WM, Berthé A, Konaté B (2012) The ambivalence of stigma and the double-edged sword of HIVIAIDS intervention in Burkina Faso. Soc Sci Med 74: 1037-1044.

14. Flood E (2005) Health-related quality of life in adoults with hemophilia Hemophilia 90: 846-850.

15. Beeton K, Neal D, Lee C (2005) An exploration of health-related quality of life in adults with haemophilia--a qualitative perspective. Haemophilia 11: 123-132.

16. Fromm E (1952) Psychoanalysis and Religion, Psychoanal. Rev: New Haven Yale University Press.

17. Diener E, Suh E, Oishi S (1997) Recent findings on subjective well-being. Indian Journal of Clinical Psychology 24: 25-41.
18. Nazzaro AM, Owens S, Hoots WK, Larson KL (2006) Knowledge, attitudes, and behaviors of youths in the US hemophilia population: results of a nationa survey. Am J Public Health 96: 1618-1622.

19. Pandey GS, Panigrahi I, Phadke SR, Mittal B (2003) Knowledge and attitudes towards haemophilia: the family side and role of haemophilia societies. Community Genet 6: 120-122.

20. Arif MO, Fatmi Z, Pardeep B, Ali T, Iqbal H, et al. (2008) Attitudes and perceptions about prenatal diagnosis and induced abortion among adults of Pakistani population. Prenat Diagn 28: 1149-1155.

21. Markova I, Forbes CD, Inwood M (1984) The consumers' views of genetic counseling of hemophilia. Am J Med Genet 17: 741-752.

22. Ngim CF, Lai NM, Ibrahim H, Ratnasingam V (2013) Attitudes towards prenata diagnosis and abortion in a multi-ethnic country: a survey among parents of children with thalassaemia major in Malaysia. J Community Genet 4: 215-221.

23. Carvalhosa AM, Henrard S, Lambert C, Hermans C (2013) Physical and mental quality of life in adult patients with haemophilia in Belgium: the impact of financial issues. Haemophilia.

24. Nercissians, E. (2007) Anthropology of Sexuality, Afkar Publication, Tehran.

25. Gregory M, Boddington P, Dimond R, Atkinson P, Clarke A, et al. (2007) Communicating about haemophilia within the family: the importance of context and of experience. Haemophilia 13: 189-198.

26. Beeton K, Neal D, Watson T, Lee CA (2007) Parents of children with haemophilia--a transforming experience. Haemophilia 13: 570-579.

27. Kang HS, Kim WO, Jeong Y, Kim SY, Yoo KY (2012) Effect of a self-help program for mothers of hemophilic children in Korea. Haemophilia 18: 892-897.

Citation: Zeinalian M, Merghati-Khoei E, Azin SA, HashemzadehChaleshtori M (2014) Help-seeking Behaviours among Haemophilia Community in Central Iran: A Qualitative Study. J Blood Disorders Transf 5: 214. doi: 10.4172/2155-9864.1000214 